Studia Anglica Posnaniensia 46/1, 2010

doi: 10.2478/v10121-009-0030-5

\title{
SPONTANEOUS USE OF VOCABULARY LEARNING STRATEGIES
}

\author{
JERZY ZYBERT
}

University of Warsaw

\begin{abstract}
The paper argues that language learners employ learning strategies naturally. To corroborate the claim it presents a research on vocabulary learning strategies and provides a quantitative and qualitative analysis of the findings and concludes with some pedagogical suggestions.

\section{Introduction}

Contemporary language teaching methodology considers vocabulary to be the most important aspect of foreign language learning. Consequently, among other things it has been widely acknowledged that language students can be effectively trained in using a number of learning strategies which they are subsequently able to exploit intentionally. This has been documented in a number of studies (e.g. Droździał-Szelest 1977; Zybert 2001; Ph.D. and M.A. dissertations devoted to the theme). On the other hand, teachers also observe that students commonly use various strategies impulsively, without any prior training, not even being aware of the fact. They do so because they "do not come to the classroom empty-handed. They bring with them an already established set of instincts, skills and characteristics, which will help them learn another language" (Halliwell 1998: 3). What strategies untrained learners employ depends on a number of individual differences. It is claimed here that two variables that are the most crucial for using strategies are the learner's age and proficiency level. Age, first of all, determines the degree of practical experience in formal learning the learner has attained; consequently, it is this experience that makes him attempt to discover, mostly subconsciously, his individual ways of effective learning. Clearly, older learners are more experienced and self-conscious than younger ones are so it is expected that they should also use more strategies. On the other hand, the learning experience must result in greater self-confidence, thus their strategies ought to be also more
\end{abstract}


complex and sophisticated. This is due to the fact that around puberty logical memory starts taking over mechanical memory and abstract thinking over concrete thinking; moreover, their longer concentration span and memory quality increase considerably. Thus their overall higher educational development and experience gives them a natural cognitive advantage over younger students, especially if they are beginners (Komorowska 1999: 44). Similarly, the actual extent of communicative competence that non-beginners have attained also affects their potential for subconscious spontaneous use of strategies. In line with the above assumptions the research presented in the paper was carried out on school learners of English, who are of special concern in the present-day educational policy in Poland; two age groups were investigated: young beginners (older children) and pre-intermediate young adolescents.

\section{Objectives}

The title of the paper explicitly implies that learners use strategies naturally and impulsively while learning a language. They evidently do so to facilitate learning. This is most conspicuous in the case of vocabulary learning. Since it is not apparent what strategies untrained learners use of their own accord this study aims to identify the range of strategies these students employ - it is also assumed that the actual use of the strategies depends on the two stable factors mentioned above, namely their age and proficiency level. Consequently, two groups of learners differing by these two factors were investigated.

The major purpose of the research was thus to show that language learners employ vocabulary learning strategies spontaneously, i.e. without receiving any prior training in using them. Recognition of the strategies used naturally should be of particular importance and interest to teachers. The findings were intended to be used for comparison between the groups with regard to the number of strategies employed, the frequency of use and their type. Secondly, the wish to explore the query to obtain plausible results seems worth pursuing as, on the one hand, the findings can endow language teachers with a clearer insight into why some young learners are more effective than others and, on the other, the identification of their strategies should help teachers to efficiently direct and supervise both poor and good students. This should guide them in training students accordingly by adopting an individualized stance in language instruction. With the above objectives in mind the main intention of the research was to recognize the vocabulary learning strategies (henceforth, VLSs) that young beginners and somewhat older intermediates characteristically use naturally in the formal setting with the view of likely adopting/adapting them for pedagogical purposes. ${ }^{1}$

1 It is assumed that the significance of vocabulary for the development of communicative 
Additionally, it needs to be mentioned that the investigations purposefully did not consider the distinction between the use of strategies in the classroom and outside of it - this decision was based on the evidenced fact that all the investigated subjects, particularly the young ones, were exposed to the foreign language only in formal situations and learned it exclusively in the classroom and at home but did not engage in functional language use outside of the two settings due to their overall insufficient competence and resources and lack of social opportunity.

\section{Subjects}

The research was conducted on two groups of school learners of English at the beginning of the $2009 / 10$ school year. ${ }^{2}$

\section{Group A}

The sample consisted of 380 students (198 girls and 182 boys) of 9 years of age. They were all native speakers of Polish, categorized as English beginners even though they had just started their third year of learning the language ${ }^{3}$ in different primary schools in central and eastern Poland. In spite of approximately 140 hours of previous instruction, they were estimated as having little proficiency in English. It is important to note that the scrutinized groups were carefully selected, the criterion being the learners' unfamiliarity with the idea of language learning strategy - during their first two years of learning English the pupils were taught by teachers other than by those who taught them in their third year, i.e. when the research was being conducted. Until that time the subjects had not been trained in strategy use nor even had an idea of what a learning strategy could be. It was these new teachers that took care of distributing and collecting the research instrument for examination. As they were vocationally qualified (they hold B.A. in EFL teaching and are preparing their M.A. projects) they only started training their students in using language learning strategies after the investigation and reported that students welcomed the training with considerable enthusiasm, especially that many of them realized then that they actually were already employing a number of strategies.

competence is clear and does not require any argumentation.

I am indebted to my in-service M.A. students for helping me to collect data.

The amount of their exposure to the language prior to the research was on average 140 hours. 


\section{Group B}

This group was comparatively smaller: it included 135 students (68 girls and 67 boys) aged 12, first grade students in lower secondary schools also in central and eastern Poland. The whole population was considered homogeneous: the length of learning English and the amount of input they had received was very much the same; despite the fact that they had learnt the language for six years in the primary school they were estimated to be at the pre-intermediate level and with still rather poorly developed language skills. The number of subjects was considerably smaller due to strict observation of the selection criterion - the same as for the previous sample: students had to be unfamiliar with language learning strategies. The teachers who administered the research were all new to the students and made sure that students had not been informed about learning strategies.

\section{Instruments}

The data collection instruments were two questionnaires specially designed for the investigation. They were constructed after a pilot study; first, two in representative groups of students were surveyed: 34 pupils in category A (young beginners) and 26 in category B (pre-intermediate young adolescents). The surveys showed that even though the term "strategy" had not been used in earlier talks with them, the students' answers demonstrated clearly that they actually did use a number of strategies. The students were asked to report on their use of "knacks" in learning words by answering the plain and easy question: "What do you do to learn a new English word that you hear or encounter in a text?" Admittedly, a few students stated that they did not know or did not use any special ways of leaning words, which meant that they did not use any strategy. Nevertheless, the remaining majority provided relevant answers and it was from these that vocabulary learning strategies actually employed were extrapolated. The identified ones enabled designing the questionnaires; they were based on 947 instances of VLSs used by the young beginners and on 863 ones used by the pre-intermediate young adolescents. It is also obvious that students displayed the use of various strategies, their numbers ranging from three to ten in Group A and from six to seventeen in Group B. These numbers are taken as indicative of individual students' abilities or even of language learning aptitude. After a careful examination of the questionnaires respective strategies were identified among the students' indications and were subsequently included in the two questionnaires used in the research proper. As could be expected, they were administered to the students in Polish.

For group A fifteen different strategies were discerned; however, four were unclear, difficult to classify and so sporadic that, in consequence, they were 
disregarded and excluded from the research instrument. The remaining eleven were selected and included in Questionnaire A that was used to scrutinize Group A students participating in the research. The subjects' answers served as data for subsequent analysis.

Ultimately, this questionnaire related to the following distinct strategies:

$\begin{array}{ll}\begin{array}{ll}\text { Question } \\ \text { no. }\end{array} & \text { Strategy } \\ 1 & \text { Imagery } \\ 2 & \text { Grouping } \\ 3 & \text { Inferencing } \\ & \\ 4 & \text { Resourcing } \\ 5 & \text { Memorizing } \\ 6 & \text { Translating } \\ 7 & \text { Repeating } \\ 8 & \text { Glossing } \\ \end{array}$

$9 \quad$ Consulting teacher

10 Consulting peers

$11 \quad$ Monitoring

\section{Description}

Using a mental or real picture to grasp/ remember the meaning of word

Putting words into families according to their lexical relations

Making use of current L2 linguistic knowledge to guess the meaning of word and/or hypothesizing on its meaning due to its formal similarity to L1 word

Obtaining lexical information from reference materials

Rote learning of form and meaning of word

Matching/associating the meaning of L1 word to/with L2 equivalent

Mimicking/rehearsing word uttered by model (aloud or silently)

Keeping own glossary; writing down words in exercise-book or special notebook, highlighting them in text with or without translation into L1

Asking for clarification

Asking for confirmation/clarification (reviewing with classmate)

Checking/controlling own understanding/use of word

Note that even though items 9 and 10 in the above list belong to the same category of social strategy, they were deliberately distinguished to find whether nine year olds were equally predisposed to turn for help to the two different sources.

For group B eighteen different strategies were initially distinguished; however, three were unclear, ambiguous and difficult to classify; consequently, they

$4 \quad$ This strategy refers to note-taking and actually includes what I have called learner glossing and described in detail elsewhere (cf. Zybert 2005). 
were disregarded and excluded but it was decided to add one more strategy, thus making Questionnaire B consisting of the following 16 distinct strategies:

$\begin{array}{ll}\begin{array}{ll}\text { Question } \\ \text { no. }\end{array} & \text { Strategy } \\ 1 & \text { Imagery } \\ 2 & \text { Grouping } \\ 3 & \text { Inferencing } \\ & \\ 4 & \text { Resourcing } \\ 5 & \text { Elaborating } \\ 6 & \text { Memorizing } \\ 7 & \text { Key-word } \\ & \\ 8 & \text { Contextualizing } \\ 9 & \text { Reviewing } \\ 10 & \text { Translating } \\ 11 & \text { Repeating } \\ 12 & \text { Glossing }\end{array}$

Description

Using a mental or real picture to grasp/ remember the meaning of word

Putting words into families thematically or according to their lexical relations

Making use of current L2 linguistic knowledge to guess meaning of word and/or hypothesizing on its meaning due to its formal similarity to L1 word

Obtaining lexical information from reference materials

Linking new information with current knowledge

Rote learning of form and meaning of word

Relating L2 word to L1 word due to resemblance, associating new word with another, familiar one

Putting a word in a meaningful context

Searching the mental lexicon to check for the new word

Matching/associating the meaning of L1 word to/with L2 equivalent

Mimicking/rehearsing word uttered by model (aloud or silently)

Keeping own glossary; writing down words in exercise-book or special notebook, highlighting them in text with or without translation into L!

13 Consulting teacher

Asking clarification checks

14 Consulting peers

Asking confirmation/clarification checks (reviewing with classmate)

$15 \quad$ Monitoring

16 Selective attention

Checking/controlling own understanding/ use of word

Attending to lexical details the learner decides to be of individual interest or actual need 
A comparison of the two lists shows that four more strategies were reported by the pre-intermediate young adolescents as identified in the pilot surveys. These were: elaborating, contextualizing, reviewing and selective attention. It is notable that whereas the younger learners used only one metacognitive strategy ${ }^{5}$ (self-monitoring), the older ones used one more (selective attention) - this is attributed to their now higher cognitive academic language proficiency and is linked to their age and experience. This finding agrees with the assumption advanced in the Introduction above, namely, that age and proficiency level benefit older and higher level learners in spontaneous strategy use. It must be explained that one more cognitive strategy, namely, key-word, was added deliberately despite the fact that it was not identified in the pilot survey. Since this strategy is generally considered very important and is found in probably all taxonomies, it was hypothesized that it may have been omitted in the pilot survey only accidentally and the researched students might still use it.

The questionnaires (see Appendices) were designed with the intention to obtain information about the students' frequency of use of the particular strategies in four dimensions, namely: always - often - sometimes - never. Their indications were meant to recognize the strategies they actually do employ and their intensity.

5. Findings (the figures are provided in percentage points (\%))

$\begin{array}{lcccc}\text { Group A } & \text { always } & \text { often } & \text { sometimes } & \text { never } \\ \text { 1 Imagery } & 26 & 34 & 26 & 14 \\ \text { 2 Grouping } & 26 & 52 & 12 & 10 \\ \text { 3 Inferencing } & 46 & 30 & 10 & 14 \\ \text { 4 Resourcing } & 57 & 17 & 21 & 5 \\ \text { 5 Memorizing } & 72 & 20 & 4 & 4 \\ \text { 6 Translating } & 65 & 33 & 2 & 0 \\ \text { 7 Repeating } & 46 & 42 & 6 & 6 \\ \text { 8 Glossing } & 32 & 53 & 10 & 5 \\ \text { 9 Consulting teacher } & 6 & 8 & 27 & 59 \\ \text { 10 Consulting peers } & 20 & 38 & 28 & 14 \\ \text { 11 Monitoring } & 22 & 31 & 18 & 29\end{array}$

5 Metacognition involves conscious thinking of one's own learning processes and achievement. 


\section{Group B}

1 Imagery

$22 \quad 39$

2 Grouping

31

39

3 Inferencing

53

4 Resourcing

59

5 Elaborating

18

6 Memorizing

7 Key-word

8 Contextualizing

9 Reviewing

12

10 Translating

63

11 Repeating

12 Glossing

13 Consulting teacher

\section{Analysis and discussion}

The findings indicate that the most popular strategies among young beginners are: memorizing, resourcing, repeating and inferencing, respectively. Also classroom observation shows that memorizing and repeating (both memory strategies) are habitually employed by youngsters, who have scanty metacognitive capabilities and rely on rote learning and repeating (to remember), which they have been used to doing since very early in childhood, especially if they attended kindergartens. The high rank of resourcing is somewhat unexpected but suggests that these learners must already be quite self-reliant (autonomous?). They may have developed the trait in the process of their general education and home upbringing which apparently promoted initiative and creativity. The high figure for inferencing is rather surprising since it actually requires quite a lot of cognitive effort on the part of young learners and rather/somehow contradicts their memory orientation.

The surprisingly low use of strategy 9 (consulting teacher) by young beginners is presumably tied to learners' motivation, anxiety and attitude. Young learners' motivation for learning anything at school usually stems from their desire to please the teacher; however, they also fear that that their frequent questions and confirmation / clarification checks can be taken for their incompetence and can spoil the positive image that the teacher may have of them. Thus, in order to save a positive face their fear creates anxiety and strong reservations, which is a kind 
of tactic in an attempt to preserve the teacher's favour. On the other hand, the low rank of this strategy can just as well derive from the learners' introvert predisposition or from their attitude towards the teacher whose poor rapport with the class can clearly demotivate learners and withdraw their interest in learning. The effect of age is also visible in older learners' greater willingness to consult the teacher their learning experience tells them that turning to the teacher is the quickest way to obtain needed information. On the other hand, memorizing and translating are very frequent strategies used in both age groups.

It is also noteworthy to remark that not a single instance of the key-word strategy was reported ${ }^{6}$ in either group; although this strategy is often considered to be highly effective and recommended in literature, it is generally observed, too, that learners are not keen on adopting it and often express their dislike for it when teachers attempt to train them in using them.

A few implications seem to have emerged from the above study. First, students do use some vocabulary learning strategies quite spontaneously even if they are unaware of the fact; second, although they use rather few of these strategies they have a weighty potential for learning them as reported by teachers, who notice students' eagerness to adopt them; third, in line with the preceding remark students can greatly benefit from conscious and intentional use of strategies - this, however, has not emerged from this study but has been proved by a number of other, well known studies.

\section{Conclusions}

Further research is needed to find whether the VLSs used by the researched sample are typical of Polish beginners; it may be that learners-beginners in other educational systems or traditions and of different cultural background use different strategies.

Interestingly/surprisingly and contrary to claims maintained in literature relating strategy use to proficiency level the present findings show that beginners use not only few strategies in general but also few metacognitive strategies (in fact, only one) than more advanced students do (cf., e.g., O'Malley - Chamot 1990: 118). It is thus concluded that beginning level students (at any rate, young ones) use overall relatively few strategies.

It is hoped that teachers who instruct young beginners can obtain some insight into their students' potential with relation to vocabulary learning strategies they use. The findings can be exploited in actual teaching practice to encourage strategy training in the classroom to the satisfaction of both learners and teachers.

6 This finding contradicts the claim that it is "[t]he most well-attested memory technique" (Thornbury 2002: 25). 


\section{REFERENCES}

Droździał-Szelest, Krystyna

1977 Language learning strategies in the process of acquiring a foreign language. Poznan: Motivex.

Halliwell, Susan

1998 Teaching English in the primary classroom. Harlow: Longman.

Komorowska, Hanna

1999 Metodyka nauczania języków obcych [The methodology of foreign language teaching]. Warszawa: WSiP.

O’Malley, J. Michael - Anna Uhl Chamot

1990 Learning strategies in Second Language Acquisition. Cambridge: Cambridge University Press.

Thornbury, Scott

2002 How to teach vocabulary. Harlow: Longman

Zybert, Jerzy

2001 "Language learning strategies: Some pedagogical implications", Scripta Neofilologica Posnaniensia 3: 151-159.

2005 “Another learning strategy?”, Studia Anglica Posnaniensia 41: 199-209.

2009 "Young learners' contribution to foreign language learning", Scripta Neophilologica Posnaniensia 10: 185-191. 


\section{APPENDICES}

(the English version of the questionnaire administered to the subjects in their L1)

App. 1

To each statement indicate your answer:

1. I visualize the meaning of the word (imagine, draw a simple picture, link it with a real object, act, event)

$$
\text { always - often - sometimes - never }
$$

2. I group words that look alike (are similar in form), are related in a way, refer to similar ideas or fields

$$
\text { always - often - sometimes - never }
$$

3. I try to guess the meaning of a word using my knowledge of English grammar and/or by relating it to a Polish word

$$
\text { always - often - sometimes - never }
$$

4. I check the meaning/use of words in dictionaries, pay attention to them when heard/seen in the media

$$
\text { always - often - sometimes - never }
$$

5. I learn words by heart

$$
\text { always - often - sometimes - never }
$$

6. I translate English words into Polish equivalents

$$
\text { always - often - sometimes - never }
$$

7. I pronounce/rehearse silently words said by teacher or spoken on TV (I imitate the speaker)

$$
\text { always - often - sometimes - never }
$$

8. I keep my own glossary: write down all words in my exercise-book or a special notebook; I highlight them in the text

$$
\text { always - often - sometimes - never }
$$

9. I ask the teacher to provide information about unfamiliar words

$$
\text { always - often - sometimes - never }
$$

10. I ask peers to confirm my understanding of words and/or clarify their meaning and use

$$
\text { always - often - sometimes - never }
$$


11. I check/control my understanding of difficult words when I hear or read or use them

$$
\text { always - often - sometimes - never }
$$

App. 2

1. I visualize the meaning of the word (imagine, draw a simple picture, link it with a real object, act, event)

$$
\text { always - often - sometimes - never }
$$

2. I group words that look alike (are similar in form), are related in a way, refer to similar ideas or fields

$$
\text { always - often - sometimes - never }
$$

3. I try to guess the meaning of a word using my knowledge of English grammar and/or by relating it to a Polish word

$$
\text { always - often - sometimes - never }
$$

4. I check the meaning/use of words in dictionaries

$$
\text { always - often - sometimes - never }
$$

5. I associate a new word with what I already know

$$
\text { always - often - sometimes - never }
$$

6. I learn words by heart

$$
\text { always - often - sometimes - never }
$$

7. I try to tie L2 word to L1 word due to resemblance, associating it with another, familiar one

$$
\text { always - often - sometimes - never }
$$

8. I try to put a word in a meaningful context

$$
\text { always - often - sometimes - never }
$$

9. I attempt remember if I have already encountered the new word

$$
\text { always - often - sometimes - never }
$$

10. I translate English words into Polish equivalents

$$
\text { always - often - sometimes - never }
$$

11. I pronounce/rehearse silently words said by teacher or spoken on TV (I imitate the speaker)

$$
\text { always - often - sometimes - never }
$$


12. I keep my own glossary: write down all words in my exercise-book or a special notebook; I highlight them in the text

$$
\text { always - often - sometimes - never }
$$

13. I ask the teacher to provide information about unfamiliar words

$$
\text { always - often - sometimes - never }
$$

14. I ask peers to confirm my understanding of words and/or clarify their meaning and use

$$
\text { always - often - sometimes - never }
$$

15. I check/control my understanding of difficult words when I hear or read or use them

$$
\text { always - often - sometimes - never }
$$

16. I pay attention to individual new words when I see/hear/them in the media

$$
\text { always - often - sometimes - never }
$$

*This article is an extended version of an earlier article (Zybert 2009) which considered only the nine year olds discussed in the present paper. 